\title{
Caribbean Fruit Fly Management in Florida Peaches ${ }^{1}$
}

\section{Amanda Coleen Hodges and Cory Penca ${ }^{2}$}

The Caribbean fruit fly, Anastrepha suspensa (Figure 1), is a member of the fly family Tephritidae, which contains some of the most destructive fruit pests in the world. It is roughly $1 / 3$ of an inch long and about the size of a common housefly. The wings are clear with amber lines forming a distinctive pattern. The body is yellow-brown. Larvae are white cylindrical maggots reaching roughly $1 / 3$ of an inch in length and slightly tapered toward one end. Larvae can be found feeding inside fruit, forming soft patches in areas where feeding has occurred. Larvae exit the fruit to pupate in the soil, though occasionally pupae may be found inside the fruit.

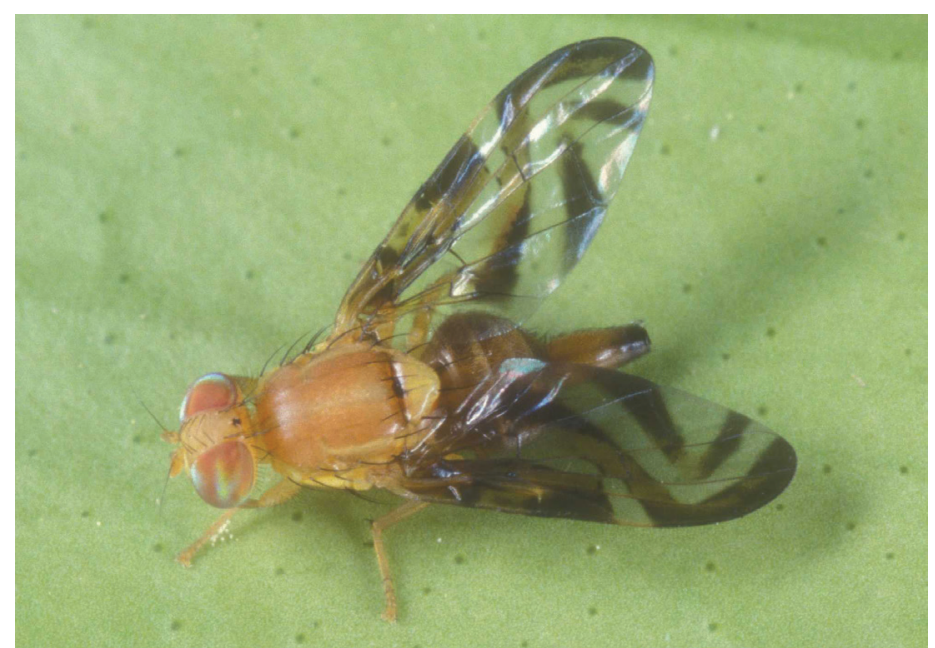

Figure 1. An adult female Caribbean fruit fly, Anastrepha suspensa. Credits: Lyle Buss, UF/IFAS
Major hosts of the Caribbean fruit fly in Florida include guava, loquat, and Suriname cherry. The range of the Caribbean fruit fly extends from the Greater Antilles northward into peninsular Florida, but it is not found in Georgia and South Carolina, making the Caribbean fruit fly a pest problem unique to Florida peach production in the United States. As a tropical species, the Caribbean fruit fly does not survive well in cooler climates. In Florida it is believed that winter survival is limited to warmer coastal areas and the southern half of the state, with fruit flies gradually moving northward and inland as temperatures rise. This may account for differences in pest pressure in different peach growing areas, because early-season peaches will be more at risk of fruit fly damage in areas where flies successfully overwinter.

\section{Damage to Peaches}

The Caribbean fruit fly lays eggs in the peach fruit by piercing the skin with her ovipositor. Eggs hatch, and the larvae feed on the flesh of the fruit, rendering the fruit unmarketable (Figure 2). The site of oviposition can be identified by the presence of clear, sappy exudate emanating from the point where the fruit was pierced, however feeding by several other insects, including stink bugs, can cause damage of similar appearance. Caribbean fruit flies preferentially oviposit in mature, ripening fruit. Damage in early-season peach orchards is more likely to occur late in the season (May or later), coinciding with warmer temperatures. The risk of Caribbean fruit fly damage increases during years with mild winters or late harvests. Orchards in

1. This document is ENY343, one of a series of the Entomology and Nematology Department, UF/IFAS Extension. Original publication date April 2019. Visit the EDIS website at https://edis.ifas.ufl.edu for the currently supported version of this publication.

2. Amanda Coleen Hodges, associate Extension scientist and Doctor of Plant Medicine program director; and Cory Penca, graduate research assistant; Entomology and Nematology Department; UF/IFAS Extension, Gainesville, FL 32611.

The Institute of Food and Agricultural Sciences (IFAS) is an Equal Opportunity Institution authorized to provide research, educational information and other services

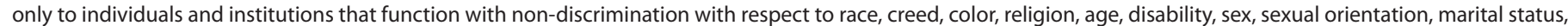

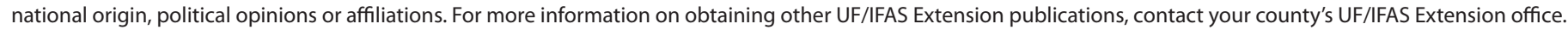
U.S. Department of Agriculture, UF/IFAS Extension Service, University of Florida, IFAS, Florida A \& M University Cooperative Extension Program, and Boards of County Commissioners Cooperating. Nick T. Place, dean for UF/IFAS Extension. 
the southernmost range of commercial peach production and orchards situated in a warmer microclimate may also be vulnerable to Caribbean fruit fly damage.

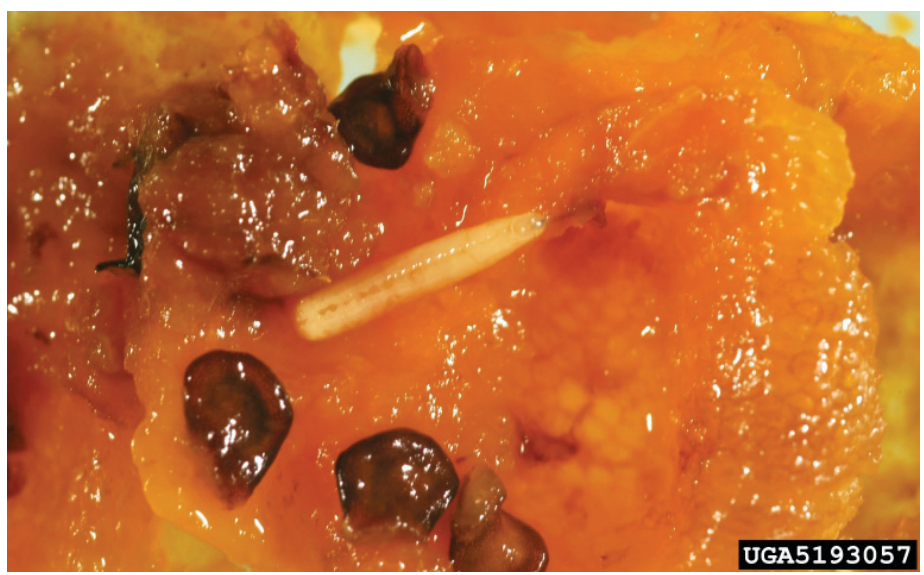

Figure 2. Larvae of a fruit fly (Anastrepha sp.) feeding on the flesh of a pepper fruit. Larval feeding renders fruit unmarketable.

Credits: Florida Department of Agriculture. Used here under Creative Commons license CC BY 3.0 US. Source: bugwood.org

\section{Management}

\section{Cultural Management}

Early-season peaches in Florida can escape Caribbean fruit fly damage as the range and abundance of fruit flies is reduced during the winter. If harvest is extended into late May, May and June fruit are more likely to be exposed to the Caribbean fruit fly. This may be more problematic in "u-pick" operations, which tend to extend their harvests beyond the early-season market window that constrains commercial operations. Because the fly prefers ripe fruit, the sooner any soft, ripened fruit are removed from the orchard the less likely the fruit will be damaged. Any unharvested fruit left on the tree may serve as a site for fruit fly reproduction, allowing populations to build locally; however, it is not clear if this will lead to increased fruit fly problems the following season. Another factor that may influence the abundance of Caribbean fruit flies around the orchard includes the presence of other host fruit trees, such as loquat and Surinam cherry, which produce fruit shortly before peaches. By providing a fruit source for the Caribbean fruit fly, these hosts may draw flies into the area and allow populations to build up before moving into the peach orchard.

\section{Monitoring}

The Caribbean fruit fly can be monitored using a variety of traps, including Jackson, McPhail (Figure 3), and multilure traps. Torula yeast is commonly used as a bait for attracting flies to the trap. Traps are only effective for monitoring populations and do not provide control of fruit flies. Information from trap captures can be used to make decisions about pesticide applications or to evaluate the efficacy of any management practices. By limiting pesticide applications to periods when traps detect fruit flies in the orchard, growers can save money and conserve beneficial insects. Because Caribbean fruit fly populations are strongly influenced by weather and location, the need to manage may vary from year to year and from site to site; traps are a useful tool to help determine whether management is necessary in a given year at a given site.

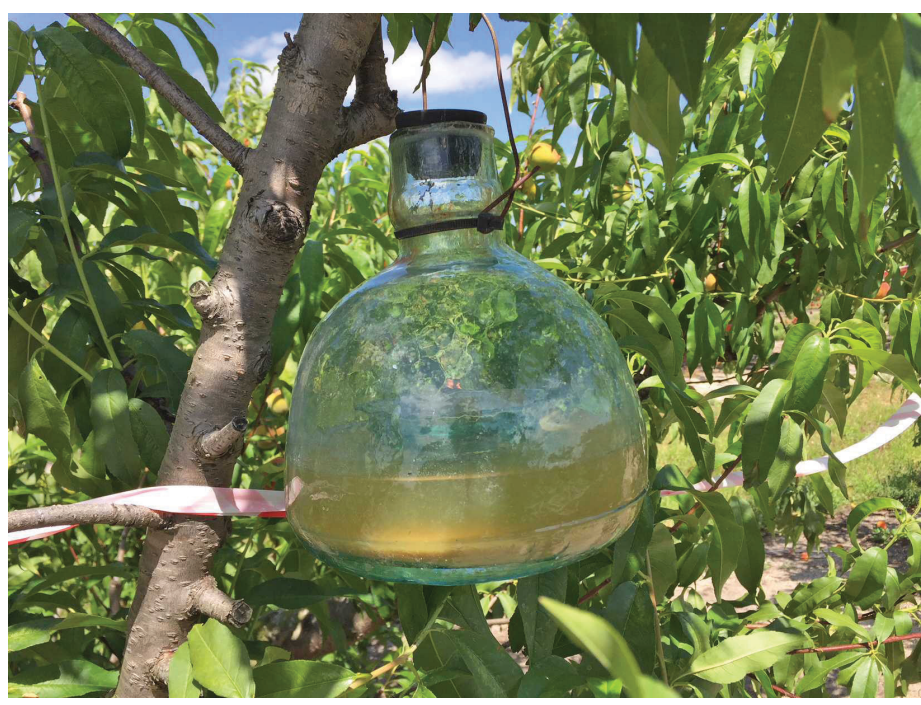

Figure 3. A glass McPhail trap in a Florida peach orchard. Flies enter the trap through an opening in the bottom and are eventually trapped by the liquid. Traps are baited with torula yeast, which attracts flies seeking a protein source.

Credits: Cory Penca, UF/IFAS

\section{Chemical Control}

Any chemical control use should be according to the label, with strict adherence to all necessary safety precautions. Because Caribbean fruit fly populations are most problematic around the time of harvest, a chemical control option with a short pre-harvest interval (PHI) is ideal. The pesticide GF-120 NF Naturalyte has been shown to be an effective option for control of the Caribbean fruit fly in Florida peaches. GF-120 contains spinosad mixed with an insect bait solution and is OMRI approved for use in organic production. As of publication, there is no PHI for GF-120 when used to control fruit flies on food crops; however, treated areas should not be entered until at least 4 hours after application. The use of Nu-Lure mixed with an insecticide such as Malathion has also been shown to be effective in control of the Caribbean fruit fly; however most effective insecticides like Malathion have a pre-harvest interval of 7 days or more, preventing their use during harvest.

When applying insecticides mixed with baits, complete coverage of the canopy is not necessary. Flies will locate droplets of the bait/pesticide mixture and ingest the 
pesticide; flies do not need to be sprayed directly. Use an ultra-low-volume sprayer with a large droplet size to increase the likelihood that flies will ingest sufficient insecticide to kill them. Applications to the underside/interior of the canopy will be protected from sun exposure and rain, preventing evaporation, degradation, or washing off of the insecticide, increasing its overall effectiveness. Table 1 summarizes chemical control options for the Caribbean fruit fly in Florida peaches. Consult the product label for the most recent product use requirements.

\section{FDACS Caribbean Fruit Fly Protocol Program}

Due to concerns about the potential spread of Caribbean fruit fly from Florida via the movement of infested peaches, the Florida Department of Agriculture and Consumer Services, Division of Plant Industry (FDACS-DPI), instituted a peach protocol to limit the risk of accidental introductions. This protocol is primarily for the shipment of Florida peaches to Texas and other export markets. The protocol involves a combination of bait sprays to reduce fly populations and trapping to verify the absence of fruit flies. Trapping and spray applications are conducted under the supervision of FDACS-DPI. More information can be found on the FDACS-DPI website (https://www. freshfromflorida.com/Divisions-Offices/Plant-Industry/ Business-Services/Registrations-and-Certifications/ Caribbean-Fruit-Fly-Protocol-Program).

\section{References}

Burns, R. E., D. L. Harris, D. S. Moreno, and J. E. Eger. 2001. "Efficacy of spinosad bait sprays to control Mediterranean and Caribbean fruit flies (Diptera: Tephritidae) in commercial citrus in Florida." Florida entomologist 84(4): 672-678.

Flores, S., L. E. Gomez, and P. Montoya. 2011. "Residual control and lethal concentrations of GF-120 (spinosad) for Anastrepha spp.(Diptera: Tephritidae)." Journal of economic entomology 104(6): 1885-1891.

Florida Department of Agriculture and Consumer Services. Caribbean Fruit Fly Protocol Program. https://www. freshfromflorida.com/Divisions-Offices/Plant-Industry/ Business-Services/Registrations-and-Certifications/ Caribbean-Fruit-Fly-Protocol-Program.

Ramos, S., M. D. C. Libran, A. Gonzalez, R. Rouse, P. Stansly, A. Wszelaki, and E. Hernandez. 2008. "Control of the Caribbean fruit fly on three peach cultivars in Adjuntas,
Puerto Rico." Proceedings of the Florida State Horticultural Society 121: 26-27.

Simpson, S. E. 1993. "Caribbean fruit fly-free zone certification protocol in Florida (Diptera; Tephritidae)." Florida Entomologist 76(2): 228-233.

Stansly, P. A., and R. E. Rouse. 2005. "Seasonal abundance of the Caribbean fruit fly Anastrepha suspensa in low-chill peaches in SW Florida and management with the spinosad bait spray GF-120." Proceedings of the Florida State Horticultural Society 118: 270-272.

Swanson, R. W., and R. M. Baranowski. 1972. "Host range and infestation by the Caribbean fruit fly, Anastrepha suspensa (Diptera: Tephritidae)." Proceedings of the Florida State Horticultural Society 85: 271-274.

Weems Jr, H. V., J. B. Heppner, T. R. Fasulo, and J. L. Nation. 2001. Caribbean fruit fly, Anastrepha suspensa (Loew) (Insecta: Diptera: Tephritidae). EENY-196. Gainesville: University of Florida Institute of Food and Agricultural Sciences. http://edis.ifas.ufl.edu/in353 
Table 1. Recommended chemical control options.

\begin{tabular}{|l|c|c|c|l|}
\hline \multicolumn{1}{|c|}{ Material } & IRAC Group & PHI & REI & \multicolumn{1}{|c|}{ Remarks } \\
\hline GF-120 NF Naturalyte & 5 & None & 4 hours & $\begin{array}{l}\text { GF-120 contains both an insecticide (spinosad) and insect bait. GF-120 } \\
\text { is labeled for most food crops. }\end{array}$ \\
\hline $\begin{array}{l}\text { Malathion + NuLure } \\
\text { insect bait }\end{array}$ & 1B & 7 days & 24 hours & $\begin{array}{l}\text { NuLure insect bait is a separate product and does not contain an } \\
\text { insecticide. It is mixed with an insecticide prior to use. Pesticides other } \\
\text { than Malathion may be used; however only insecticides labeled } \\
\text { for use on peach can be used legally in combination with NuLure } \\
\text { insect bait. }\end{array}$ \\
\hline
\end{tabular}

